\title{
Public Health News Appraisal: An Approach to Content Analysis of News Article on Public Health
}

\author{
Mehul Patel ${ }^{1}$ Pankaj Bhardwaj ${ }^{1,2}$ Deepak Saxena ${ }^{3}$ Nitin Joshi ${ }^{2}$ Nitesh Kumar ${ }^{1} \quad$ Kuldeep Singh $^{2,4}$ \\ Abhay Gaidhane $^{5}$ Quazi Syed Zahiruddin ${ }^{5}$ Yogesh Jain ${ }^{2, \odot}$
}

${ }^{1}$ Department of Community Medicine and Family Medicine, All India Institute of Medical Sciences, Jodhpur, Rajasthan, India

${ }^{2}$ School of Public Health, All India Institute of Medical Sciences, Jodhpur, Rajasthan, India

${ }^{3}$ Department of Epidemiology, Indian Institute of Public Health, Gandhinagar, Gujarat, India

${ }^{4}$ Department of Paediatrics, School of Public Health, All India

Institute of Medical Sciences, Jodhpur, Rajasthan, India

${ }^{5}$ Community Medicine, Datta Meghe Institute of Medical Sciences,

Wardha, Maharashtra, India

\author{
Address for correspondence Pankaj Bhardwaj, MD, Department \\ of Community Medicine and Family Medicine, All India \\ Institute of Medical Sciences, Jodhpur 342005, Rajasthan, India \\ (e-mail: pankajbhardwajdr@gmail.com).
}

\begin{abstract}
Keywords

- public health

- content

- newspaper article

- evaluation

Public Health News Appraisal (PHNA) is a systematic process and an important skill to be mastered by public health trainees by which the strengths, weaknesses, and validity of a news article can be identified. This process helps trainees to identify usefulness of news, recognize any potential for bias, and ascertain whether the news is trustworthy. Trainees can assess whether the news article successfully communicates the intended message to reader. PHNA checklist with 18 questions was designed to help students to achieve this objective. Responses of most of the questions in this checklist are in the form of yes, no, and can't tell. The articles can be categorized and analyzed based on the comparative PHNA score.
\end{abstract}

\section{Introduction}

In the current scenario, a common man is struggling for livelihood and doesn't have enough time to stay updated for health-related events or incidents occurring across the country and around the world. In such a situation, one of the quick and important sources of information is the newspaper media which endeavors to respond to this general request and there has been hardly a day without any health news in the media. ${ }^{1}$ Being available in all languages and accessible to all communities, newspapers enjoy a wide readership throughout the world and represent a time-honored means of disseminating printed word information. ${ }^{2}$ The objective of public health news is to promote healthy behavior in communities as well as provide information which is authentic with references and in a language people can understand.

\section{published online} May 27, 2021
DOI https://doi.org/

$10.1055 / \mathrm{s}-0041-1730126$ ISSN 0379-038X
They do contribute to generate awareness of people by publishing articles on various issues such as hygiene, immunization, sanitation, population control, environmental pollution, communicable and noncommunicable diseases, nutritional deficiency diseases, accidents, reproductive health, maternal health, child health, adolescent health, geriatric health, industrial health, mental health, and healthy life style. ${ }^{3}$ The media effect on the general public's awareness, practices, and attitude cannot be ignored. The influence in health care is very often too deep that community usually changes their treatment option in view of health news promulgated in the media. ${ }^{4}$ Hence the role of media becomes very vital and important in disseminating the correct information; however, there are evidences that some reports in the media contain wrong and potentially dangerous information which could harm those who trust these reports. ${ }^{4}$
(C) 2021. National Academy of Medical Sciences (India).

This is an open access article published by Thieme under the terms of the Creative Commons Attribution-NonDerivative-NonCommercial-License, permitting copying and reproduction so long as the original work is given appropriate credit. Contents may not be used for commercial purposes, or adapted, remixed, transformed or built upon. (https://creativecommons.org/licenses/by-nc-nd/4.0/).

Thieme Medical and Scientific Publishers Pvt. Ltd. A-12, 2nd Floor, Sector 2, Noida-201301 UP, India 
While newspaper articles are not typically the first choices for inclusion in academic research papers for their analytical content, they do provide first-hand accounts of events that have historical significance and are excellent examples of primary sources. ${ }^{5}$

A review conducted by The George Institute for Global Health India has revealed the need for contextualizing health stories both in the public health as well as the media context, identify and bridge the skill/knowledge gaps, revisit concepts of journalistic objectivity and neutrality especially when science is challenged by those who do not have evidence in their favor, and connect journalism and science for the public good. ${ }^{6}$

In recent years, many public health teaching institutions with postgraduate courses have included public health news review/analysis as a part of their teaching curriculum but there is no clarity and uniformity about process on its delivery. These public health trainees need to build their capacity to critically analyze news articles to understand the message conveyed and its usefulness. There are structured guidelines for critically evaluating journal articles but in spite of comprehensive literature review no systematic/structured guidelines could be retrieved by the authors that might assist learners for critical evaluation of a newspaper article.

The current article presents one such effort taken by three schools of public health (two affiliated to state and one affiliated to central agency) to develop structured checklist (shown in - Supplementary Appendix A, available in the online version) for critically evaluating newspaper article. As a part of this, postgraduate trainees under supervision of faculties have started public health news analysis. The current version was framed after the feedback from faculty members and students over the period of two years

\section{Development of Public Health News Appraisal (PHNA) Checklist}

The public health news appraisal (PHNA) checklist for critical appraisal of news items was framed with the triangulation of observations from critical evaluation of various epidemiological guidelines and news articles published in various newspapers with a focus on health.

News articles are typically written in the inverted pyramid style, most important information at the beginning of the article and increasingly less important details toward the end of the article as shown in - Fig. 1. If structured this way, an article can be edited from the bottom up to make room for additional news items that might have since broken. ${ }^{7.8}$

The aim of most news articles is to answer six questions about the happenings about which they report: who, what, when, where, why, and how. ${ }^{5}$

Majority of news articles focuses on serving several purposes but that needs to be dissected under certain domains/major themes as described below and shown in - Table 1. . $^{9,10}$

- Is the article written to inform (look if the article has a clear structure and whether it provides sufficient evidence supported by facts and additional research)?

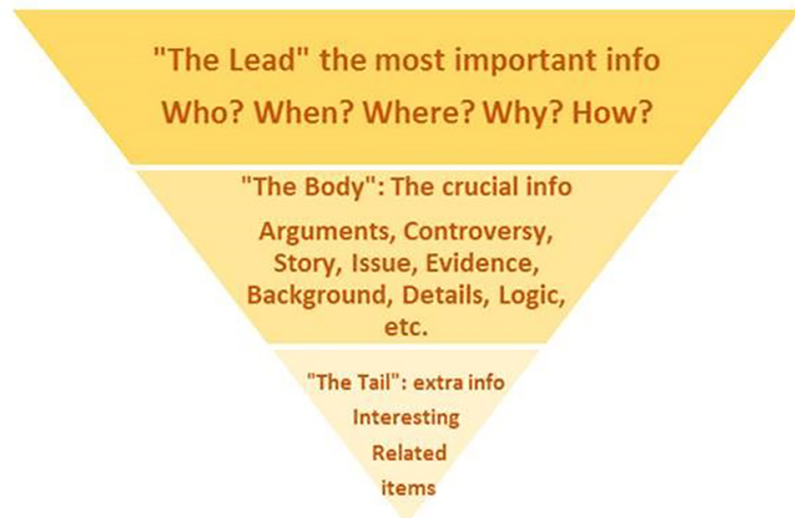

Fig. 1 Inverted pyramid style.

- Is the article written to persuade (look to find if the author has presented logical reasoning and counterarguments, opposite opinions to persuade someone about particular opinion)?

- Is the article written to entertain (see what emotions are caused by the article and how does it personally influence and inspire you)?

\section{Specific Components to Check $^{11}$}

Any news article presented by the trainee needs to be analyzed with the following essential items:

- Timeliness: News must be timely and new. A news article might not arouse interest in the reader if it is already known or content is quite old.

- Proximity: Communities are more interested learning and reflecting on what happens in their village, town, country, rather than a distant place. But sometimes when the news from a distant geography, like news on swine flu, which might also affect their community is also read cautiously.

- Conflict/controversies: Conflicts and controversies are usually the main topic selected by the newspaper as prominent public health-related news item. It may be clash between groups of people, states, countries, or organizations or controversies across various health procedures and program management or policies.

- Prominence: The community usually follows the important people that might have influence on a large will make a good news item and its impact. For example, a famous

Table 1 Identifying different types of purpose

\begin{tabular}{|l|l|l|}
\hline \multicolumn{3}{|l|}{ General and specific purposes } \\
\hline To inform & To entertain & To persuade \\
\hline To analyze & To amuse & To argue against \\
\hline To clarify & To delight & To argue for \\
\hline To discuss & To frighten & To convince \\
\hline To establish & & To criticize \\
\hline To explain & & To inspire \\
\hline
\end{tabular}

Source: Adapted from Tone and Purpose Handout. January 2009; g: ASC Eng Read. ${ }^{10}$ 
cine star coming forward and campaigning for polio eradication resulted in incremental increase in oral polio vaccine coverage.

- Government action: The passing of new law, orders, or notification of new rules concerning general people, cabinet decision, and parliament and assembly sessions or meeting makes news worthy and the community look forward for this news.

- Development projects and issues: Progress in any development projects or some development in an issue makes news which the community looks forward to.

- Human interest: An incident or an event of human interest will be news and is a welcome read by community.

- Follow-up: Follow-up and update of some events or an issues make news.

\section{What Makes a News Valid? ${ }^{12}$}

The following factors make a news valid:

- Accuracy: Accuracy is basic to any news item. All facts and reality provided in the news item should be accepted by readers without questions. What factual accuracy really means is that every statement, every name, date and age, quotation, definite word or expression or sentence must be precise and present the true facts.

- Balance: If the news is about a controversy, the writer should give both sides of story. News should be balanced in content, meaning, and in the matter of emphasis and complements.

- Objectivity: The writer should not mix their opinion in the story. They should report only fact and other people's opinions without any personal bias or any outside influence.

- Current: Time is the essence of the news. Things are always changing and the news readers want the most recent information on topics of concerns or interest to them.

- Clarity: It must be united, concise, clear, and simple.

- Impact: News should induce some changes somewhere for the better.

\section{Where and How to Find Newspaper Articles? ${ }^{7}$}

Primary source of the article can be a printed newspaper. News publishers also provide e-paper and e-articles on their Web sites which also have millions of viewers. Most libraries now provide access to articles from newspapers via online databases. Nowadays social media is also playing important role in news dissemination. Google is busily scanning newspapers and making them searchable and viewable over the open Internet. A researcher can go to news.google.com to access news articles available through Google. ${ }^{7}$

The presenter should consider title, newspaper name, place of publication, published on, page number, from where article was retrieved (in print, from a database, online, etc.), media weightage, and language while finding articles.

\section{How to Present Newspaper Articles}

Following points should be taken into account while presenting news article:
1. Title or Headline: Headlines desire to perform two functions: (a) to summarize and (b) to draw the reader's attention to the full-text newspaper article. Sometimes headlines make a loose, incomplete, or deceptive replacement for full-text news reports in several ways-by directing the reader's attention to an aspect of the story; by highlighting the subject in a nonobjective, yet interesting way; and by oversimplifying the full-text content, while masking other "important" information. Thus, headlines may underrepresent, or overrepresent, and hence misrepresent the news stories. Do the headlines and stories match ${ }^{13}$

We can consider three main types of titles. ${ }^{14}$

- Declarative title: These titles include what news say (main conclusions), not just what they cover, for instance.

- Descriptive or neutral titles: A descriptive title only reports the subject of the news and does not reveal the main outcome or conclusion.

- Interrogative titles: These types of titles point out the subject of the article in the form of a question that appeal to the interest of readers.

2. Summarize the main points of the article, topic discussed, or highlights in own words (3-5 bullet points or sentences).

3. Purpose of the article ${ }^{9}$ : State the article's purpose. As many articles may have multiple purposes (e.g., to entertain and persuade). Try to identify what you consider to be the prime purpose, explaining your reasons. Explain your intent option by using the article's quote word or phrase to help your answer.

4. Tone of the article:Identify the tone of the article. Articles may have different variety of tones. You should be able to identify one significant tone, or the tone which seems to be present and apparent throughout the article. It can be critical, angry, sympathetic, passionate, satirical, approving, disapproving, or even neutral. ${ }^{9}$

5. Argument and evidence: Analyze the evidence provided to support the writer's main point, taking care to point out if there are flaws in the argument. What evidence (data, research findings, historical or economic trends, theories, opinions, stories, anecdotal evidence) does the writer offer to support that argument or evidence? Enlist the specific evidence used in the article. Is that evidence sound ${ }^{15}$

6. Validity of News ${ }^{16}$ : Validity is soundness and strength of argument. Is this evidence any good? The first challenge is to detect reliable and unreliable news media source. The matter of reliability is subjective.

Notice that the author uses the words "experts say" and then later gives a quote and identifies the speaker as a public health expert. What is his or her personal background? Is he or she a well-known expert in the field? Are they representing any organization or institute? If so, what is the organization's mission and goals? You can try doing a Google search on the expert or their organization. In what way did author use of quotations: (1) to add to the credibility of the story, (2) 
to make the story more interesting, or (3) to present differing points of view about the subject?

How did the source get its information? If the source has references, look at a few of the references to verify-do they look like reliable sources of information or data? Does it look like the writer is citing the source precisely? Use your best judgment! Cite your references to support or argue evidence.

7. Accompanying photo(s), illustrations, graphics, graphs ${ }^{17}$ : What graphics are included with the article? Does the photo/illustration used in article influence the way the story is being presented?

8. Bias of the writer:Does the writer have any hidden agenda or preference? How can you prove ( - Table 2) ${ }^{18}$

9. Generalizability of news ${ }^{19}$ : Try to find similar news published in another newspaper. What are the differences and similarities?

10. Content analysis ${ }^{20}$ : News can be coded for content analysis. Following coding criteria commonly used for content analysis of public health news.

- Valence: A positive or negative tone in reference to issue. Positive tone is where the writer portrays an aspect in issue positively. A negative tone is where words are used to focus on the challenging aspects of issue.

- Descriptors: Whether writer report it as an epidemic or outbreak situation, public health problem, or not a problem at all.

- Causes and solutions: Does the articles highlight the means of contracting disease or condition, prevention, and management methods?

- Population mentioned: Does the articles describe those having or at risk of contracting disease or health problem, such as children, adolescents, women, drug users, prostitutes, or geriatric population?

11. Newspaper summary template ${ }^{21}$ : The following template should be used to summarize the article.

- Title: include the full title or headline of the article.

Table 2 Identifying different types of bias

\begin{tabular}{|l|l|}
\hline Form of bias & Description \\
\hline $\begin{array}{l}\text { Bias by } \\
\text { commission }\end{array}$ & $\begin{array}{l}\text { Passing along errors or assumptions to sup- } \\
\text { port or refute a point of view }\end{array}$ \\
\hline Bias by omission & $\begin{array}{l}\text { Ignoring facts or statistics to support or dis- } \\
\text { prove a point of view }\end{array}$ \\
\hline Bias by selection & $\begin{array}{l}\text { Selecting only evidence that supports or } \\
\text { disproves a certain point of view }\end{array}$ \\
\hline $\begin{array}{l}\text { Bias by } \\
\text { placement }\end{array}$ & $\begin{array}{l}\text { Emphasizing only that which supports or } \\
\text { disproves a certain point of view }\end{array}$ \\
\hline $\begin{array}{l}\text { Bias by } \\
\text { interpretation }\end{array}$ & $\begin{array}{l}\text { Using only one perspective when relaying } \\
\text { information; also known as "spin" }\end{array}$ \\
\hline $\begin{array}{l}\text { Bias by policy or } \\
\text { condemnation }\end{array}$ & $\begin{array}{l}\text { Suggesting or condemning a policy or course } \\
\text { of action }\end{array}$ \\
\hline Bias by labeling & $\begin{array}{l}\text { Categorizing sources with labels that elicit } \\
\text { certain reactions, such as calling a news } \\
\text { source "expert" or "extremist" }\end{array}$ \\
\hline
\end{tabular}

Source: Adapted from Leann Davis Alspaugh OLE teaching community. ${ }^{18}$
- Author: Give the writer's full name; if there is no writer or author given, indicate if the article is an editorial or from a foreign news source.

- Newspaper: Give full name of the newspaper from which the article is extracted.

- Date: The day the article published in the newspaper.

- Subject: The overall topic that the article describes.

- Thesis: Identify what the writer is proving or arguing about the subject. Is he/she trying to convince readers to take a side? If so, what opinion is it encouraging?

- Evidence: List examples with references in the article that help to convince the reader or inform them of the subject.

- Significance: Explain why this subject is important and whom it may affect.

This way, by using PHNA any news article related to public health can be very well analyzed by the presenter.

\section{Conclusion}

This article provides a systematic method in the form of PHNA tool which can be used as a checklist to evaluate the news article related to public health in a structured and meaningful way.

\section{Conflict of Interest}

None declared.

\section{References}

1 Institute of Medicine (US) Committee on Assuring the Health of the Public in the 21st Century. The Future of the Public's Health in the 21st Century. Washington, DC: National Academies Press (US); 2002. Available at: https://www.ncbi. nlm.nih.gov/books/NBK221224/. Accessed May 3, 2020

2 Dhaar GM. Foundations of Community Medicine. 2nd ed. Noida, India: Elsevier India; 2009

3 Paul S, Singh AB. Coverage of health-related articles in major local newspapers of Manipur. J Educ Health Promot 2016;5:3

4 Ashoorkhani M, Majdzadeh R. Improving the quality of health news. Int J Prev Med 2012;3(7):440-443

5 Alderman J. Analyzing newspaper articles. Beginning library and information systems strategies. Available at: https://digitalcommons.unf.edu/bliss/24. Published online January 1, 2014. Accessed January 27, 2020

6 The George Institute for Global Health. Need for critical appraisal among journalists writing on health issues in India. Available at: https://www.georgeinstitute.org.in/news/needfor-critical-appraisal-among-journalists-writing-on-healthissues-in-india. Accessed January 27, 2020

7 Tofte M. LibGuides: evaluation of sources-a how to guide: newspaper. //lib.taftcollege.edu/EvaluationofSources/Newspaper. Accessed November 20, 2019

8 Roberts J. Inverted pyramid style. In: Writing for Strategic Communication Industries. The Ohio State University; 2016. Available at: https://ohiostate.pressbooks.pub/stratcommwriting/chapter/inverted-pyramid-style/. Accessed November 15, 2019

9 Nerdify. Guide on article analysis (with 1 analysis example). Medium. Available at: https://medium.com/@nerdify/ complete-guide-on-article-analysis-with-1-analysis-example-ddb2e993d3f. Published January 22, 2019. Accessed November 14, 2019 
10 Examples E. Tone and purpose handout. January 2009; g: ASC Eng Read. Available at: https://www.essaybot.com/sample/ essays/detail?id=202757. Accessed November 15, 2019

11 Discuss about ingredients of the news? Owlgen. Available at: https://www.owlgen.in/discuss-about-ingredients-of-thenews/. Accessed November 15, 2019

12. Owlgen.What is news values in journalism? Available at: https://www.owlgen.in/what-is-news-values-in-journalism/. Published December 26, 2017. Accessed May 3, 2020

13 Ifantidou E. Available at: Newspaper headlines and relevance: ad hoc concepts in ad hoc contexts. J Pragmatics 2009;41(4):699-720

14 Jamali HR, Nikzad M. Article title type and its relation with the number of downloads and citations. http://eprints. rclis.org/19669/1/Jamali_title.pdf. Published 2011. Accessed November 15, 2019

15 Fred Meijer Center for Writing. A brief overview of the article analysis. Available at: https://www.gvsu.edu/cms4/asset/ CC3BFEEB-C364-E1A1-A5390F221AC0FD2D/business_article_analysis_gg_final.pdf. Accessed November 16, 2019

16 What is a "good" source? Determining the validity of evidence: professional writing program. Available at: https:// umd.instructure.com/courses/1082806/pages/what-is-agood-source-determining-the-validity-of-evidence. Accessed May 4, 2020

17 McGraw-Hill Student Success Online Learning Center. The CARS checklist (credibility, accuracy, reasonableness, support). Available at: http://novella.mhhe.com/sites/0079876543/student_view0/research_center-999/research_papers30/conducting_web-based_research.html. Accessed November 20, 2019

18 std. MDS BAS 497 Ethical Issues with Media Bias Web site. Available at: http://mediabiasmds-bas497.weebly.com/. Accessed November 16, 2019/std

19 Maier S. All the news fit to post? Comparing news content on the web to newspapers, television, and radio. Journalism \& Mass Communication Quarterly 2010;87:548-562

20 Thomas $\mathrm{CN}$, Inokuchi $\mathrm{D}$, Lehman $\mathrm{T}$, Ledsky R, Weldy A. Overweight and obesity in local media: an analysis of media coverage in CDC-funded communities. Prev Chronic Dis 2017; 14:E126

21 Illinois Library. Newspapers and magazines as primary sources: step 1-article. Available at: //guides.library.illinois. edu/c.php?g=593567\&p=4106243. Accessed May 4, 2020 